\title{
Observation of Clouds Using the CSIR Transportable LIDAR: A Case Study over Durban, South Africa
}

\author{
Lerato Shikwambana $^{1,2}$ and Venkataraman Sivakumar ${ }^{1}$ \\ ${ }^{1}$ School of Chemistry and Physics, University of KwaZulu-Natal, Private Bag X54001, Durban 4000, South Africa \\ ${ }^{2}$ CSIR National Laser Centre, P.O. Box 395, Pretoria 0001, South Africa
}

Correspondence should be addressed to Lerato Shikwambana; lshikwambana@gmail.com

Received 29 February 2016; Revised 20 June 2016; Accepted 21 August 2016

Academic Editor: Stefania Bonafoni

Copyright $\odot 2016$ L. Shikwambana and V. Sivakumar. This is an open access article distributed under the Creative Commons Attribution License, which permits unrestricted use, distribution, and reproduction in any medium, provided the original work is properly cited.

\begin{abstract}
The Council for Scientific and Industrial Research (CSIR) transportable Light Detection And Ranging (LIDAR) was used to collect data over Durban $\left(29.9^{\circ} \mathrm{S}, 30.9^{\circ} \mathrm{E}\right)$ during 20-23 November 2012. Aerosol measurements have been carried out in the past over Durban; however, no cloud measurements using LIDAR have ever been performed. Therefore, this study further motivates the continuation of LIDAR for atmospheric research over Durban. Low level clouds were observed on 20-22 November 2012 and high level clouds were observed on 23 November 2012. The low level cloud could be classified as stratocumulus clouds, whereas the high level clouds could be classified as cirrus clouds. Low level cloud layers showed high extinction coefficients values ranging between 0.0009 and $0.0044 \mathrm{~m}^{-1}$, whereas low extinction coefficients for high level clouds were observed at values ranging between 0.000001 and $0.000002 \mathrm{~m}^{-1}$. Optical depth showed a high variability for 20 and 21 November 2012 . This indicates a change in the composition and/or thickness of the cloud. For 22 and 23 November 2012, almost similar values of optical depth were observed. Cloud-Aerosol LIDAR and Infrared Pathfinder Satellite Observations (CALIPSO) revealed high level clouds while the CSIR LIDAR could not. However, the two instruments complement each other well to describe the cloudy condition.
\end{abstract}

\section{Introduction}

The detection of clouds in satellite imagery has a number of important applications in weather and climate studies [1]. In atmospheric remote sensing, cloud detection is an important step for the inversion of the parameters in the atmosphere such as temperature, humidity, and sea surface temperature to name a few [2]. Equally important in sensed image processing, cloud detection is an important foundation for many applications such as forest fires detection, environmental pollution, and waterbody monitoring [3]. The National Aeronautics and Space Administration (NASA) has a constellation of satellites called the A-Train which has passive and active sensors specifically dedicated to the study of aerosol and cloud properties from a three-dimensional perspective, exploiting simultaneous and collocated multisensor observations [4]. The A-Train satellites include the Aqua satellite with its Moderate Resolution Imaging Spectroradiometer (MODIS, http://modis-atmos.gsfc.nasa.gov/), CloudSat with its Cloud Profiling Radar (CPR, http://cloudsat.atmos.colostate.edu/), and the Cloud-Aerosol LIDAR and Infrared Pathfinder Satellite Observations (CALIPSO); all these instruments can be used to study clouds [5]. Space-based observations have the advantage of providing global spatial coverage but they do not have sufficient temporal coverage to study many atmospheric processes [6]. Ground-based observations are necessary for the long-term monitoring of atmospheric parameters that cannot be observed from available satellite-borne sensors [6]. Ground-based instruments such as sun-photometers make direct sun measurements at several wavelengths in the range between 340 and $1020 \mathrm{~nm}$, with a $1.2^{\circ}$ full field of view (FOV) which takes about $8 \mathrm{~s}$ to scan all wavelengths using a filter wheel [7]. Ground-based radars are also used to detect and study different clouds. For example, Hollars et al. [8] used a radar system for the retrievals of cloud-top heights from the Atmospheric Radiation Measurement (ARM) $35 \mathrm{GHz}$ Millimeter Wave Cloud Radar and compared it to those 
from the Geostationary Meteorological Satellite- (GMS-) 5. Similar to ARM systems, the Light Detection And Ranging (LIDAR) with high sensitivity and high temporal coverage can be used for studying clouds [9]. LIDAR retrieval of atmospheric parameters is an effective tool to characterise the time and spatial evolution of the atmospheric boundary layers as well as to investigate the physics properties of the cloud composing particle [10]. A laser ceilometer is another type of a ground-based instrument that can be used to determine the height of a cloud base, cloud cover, and cloud vertical structure [11]. A laser ceilometer has a similar type of setup as the LIDAR; it consists of a vertically pointing laser and a receiver at the same location. Many studies and observations of clouds have been made around the world using various instruments. However, in South Africa, only a few studies of this nature have been carried out using a transportable LIDAR system. Transportable LIDAR systems have an advantage over static systems as they can be moved to the desired locations where measurements are to be carried out.

For South Africa, it was found that the country could be divided into three climatic regions: the subtropical wet, the subtropical dry, and the arid. The subtropical wet region is characterised by hot summer temperatures and fully humid conditions; this is observed in the eastern parts of South Africa. The subtropical dry regions are observed in the northern parts of South Africa and are characterised by warm temperatures during dry summers. The arid region is observed in the western part of South Africa and is characterised by high temperatures [12]. However, a full description of the division of climatic areas is defined by Köppen-Geiger climate classification [13]. Figure 1 shows the different climatic regions found in South Africa (http://koeppen-geiger.vu-wien.ac.at/present.htm). The Köppen-Geiger climate classification is divided into three zones: (1) the main climatic zone, (2) precipitation, and (3) temperature. The colour scheme on the map indicates a combination of the three zones which gives a description of the climatic condition of the area. From the regions mentioned, the subtropical wet region offered the best location for our cloud studies as it is humid and allows for a higher chance of cloud formation. Durban $\left(29.9^{\circ} \mathrm{S}, 30.9^{\circ} \mathrm{E}\right)$ was the city chosen as it met all the requirements. Moreover, there were no cloud measurements reported using the LIDAR system. The campaign measurements performed at Durban are to understand the aerosol-cloud interaction later. The particular site had a fixed LIDAR system at the University of KwaZuluNatal but it is currently not operational. Moorgawa et al. [14] have made initial results on aerosols over Durban but there were no cloud measurements reported using such LIDAR. Thus, the present study further motivates the continuation of LIDAR for atmospheric research over Durban.

In this study, the CSIR transportable LIDAR system and CALIPSO were used for observing cloud structure and studying its properties. In this paper, we discuss the campaign measurements conducted in Durban, South Africa, during the end of the spring season. We show the type of clouds that were observed from 20 to 23 November 2012. In Section 2, a

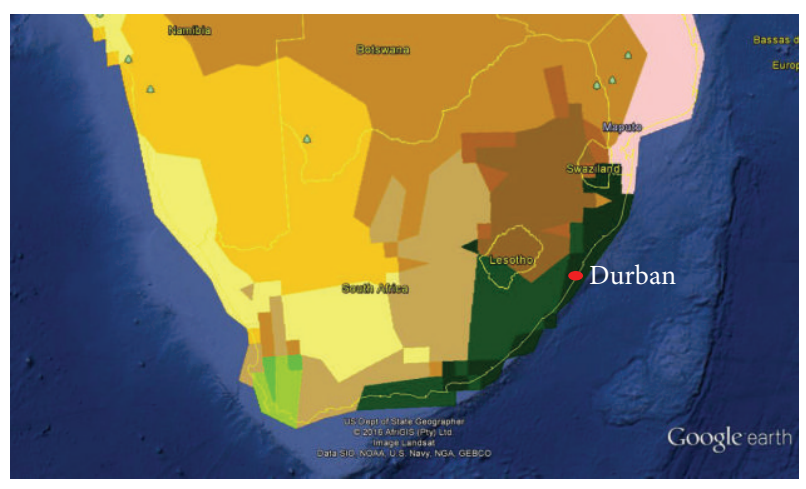

World map of Köppen-Geiger climate classification Updated with CRU TS 2.1 temperature and VASClimO v1.1 precipitation data 1951 to 2000
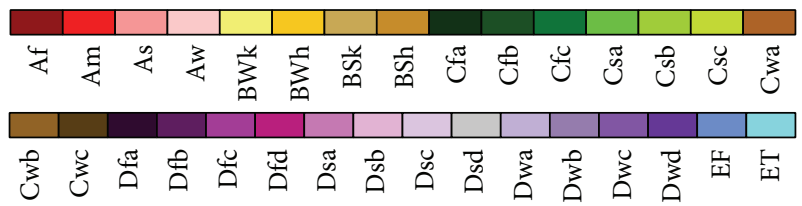

Temperature

$\mathrm{H}$ : hot arid

K: cold arid

A: hot summer

B: warm summer

C: cool summer

D: extremely continental

F: polar frost

$\mathrm{T}$ : polar tundra

FIGURE 1: Köppen-Geiger climate classification of South Africa representing different climatic regions ([13]; http://koeppen-geiger.vuwien.ac.at/present.htm). The map also shows the city of Durban, the measurement site.

description of the experimental site is given. The instruments, methodology, and results are discussed in Sections 3, 4, and 5 , respectively. Conclusions are then given in Section 6.

\section{Experimental Site}

Durban is the largest urban city in the South African province of KwaZulu-Natal and its time zone is UTC+02:00. It is situated at the south-east of South Africa and it is bound to the east by the Indian Ocean (see Figure 1). The city has a subtropical climate and experiences four seasons which are summer (December-February), autumn (March-May), winter (June-August), and spring (September-November). The rainy season is during late November through December and may extend to January.

\section{Instruments}

3.1. CSIR Transportable LIDAR System. The transportable Mie LIDAR system at the Council for Scientific and Industrial Research (CSIR), in Pretoria $\left(25.7461^{\circ} \mathrm{S}, 28.1881^{\circ} \mathrm{E}\right)$, was developed in 2007. This LIDAR has been configured into monostatic system that maximizes the overlap of the outgoing 
TABLE 1: Specifications of the CALIPSO and CSIR LIDAR system.

\begin{tabular}{lcc}
\hline Feature & CALIPSO & CSIR LIDAR \\
\hline Laser & $\begin{array}{c}\text { Nd: YAG, } \\
\text { diode-pumped, } \\
\text { Q-switched, } \\
\text { frequency doubled }\end{array}$ & $\begin{array}{c}\text { Nd: YAG, Q-switched, } \\
\text { flash lamp-pumped } \\
\text { (Continuum }{ }^{\circledR}, \\
\text { PL8010) }\end{array}$ \\
Wavelength & $532 \mathrm{~nm}, 1064 \mathrm{~nm}$ & $532 \mathrm{~nm}$ \\
Pulse energy & $110 \mathrm{~mJ} /$ channel & $140 \mathrm{~mJ}$ \\
Repetition rate & $20.25 \mathrm{~Hz}$ & $10 \mathrm{~Hz}$ \\
Receiver telescope & $1 \mathrm{~m} \mathrm{diameter}$ & $0.404 \mathrm{~m}$ \\
532 nm detectors & PMT & PMT \\
1064 nm detectors & $\mathrm{APD}$ & - \\
Polarization & $532 \mathrm{~nm}$ & $532 \mathrm{~nm}$ \\
FOV & $130 \mu \mathrm{rad}$ & $500 \mu \mathrm{rad}$ \\
Vertical resolution & $30-60 \mathrm{~m}$ & $10 \mathrm{~m}$ \\
\hline
\end{tabular}

beam with the receiver field of view [16]. The LIDAR system has been mounted in a transportable platform with a special shock absorber frame to maximize stability [16, 17]. Figure 2 shows the layout of the experiment with the three main sections of the LIDAR system, namely, the transmission, receiver, and data acquisition sections. Specifications of the CSIR LIDAR system are shown in Table 1. More details about the LIDAR can be found in an earlier article on system characteristics by Sharma et al. [17].

3.2. CALIPSO. The Cloud-Aerosol LIDAR and Infrared Pathfinder Satellite Observations (CALIPSO) can provide information about the thickness of clouds and can determine the height and types of aerosols. CALIPSO consists of three coaligned nadir-viewing instruments: the CloudAerosol LIDAR with Orthogonal Polarization (CALIOP), the Imaging Infrared Radiometer (IIR), and the Wide Field Camera (WFC). CALIOP is a sensitive LIDAR that provides high-resolution vertical profiles of aerosols and clouds. CALIOP products can be separated into two levels: (a) level 1 products are composed of calibrated and geolocated profiles of the attenuated backscatter returned signal and (b) level 2 products which are derived from level 1 products and are classified in three types: layer products, profile products, and vertical feature mask [18]. The CALIOP is sensitive to the presence of thin cloud layers and its range resolution of $333 \mathrm{~m}$ can identify small boundary layer clouds, especially in the absence of optically thick high clouds where low clouds most dramatically impact the fluxes of shortwave radiation [19]. Table 1 shows the specifications of the CALIPSO.

\section{Data Analysis and Methodology}

The LIDAR measurements were carried out from 20 November 2012 to 23 November 2012. The time duration of measurements depended on the weather situation for that day. For example, on 20 November 2012, the measurements were carried out from 10:59 local time to around 15:50 when it started to drizzle; the measurements were then discontinued. The weather varied for the different days of the measurements.

The backscatter signals were collected and their intensities measured. In general, the received signal intensity is described in terms of the LIDAR equation as given by Bangia et al. $[20,21]$;

$$
P(r)=P_{o} \frac{c \tau}{2} A \frac{\beta(r)}{r^{2}} e^{-2 \int_{0}^{r} \sigma\left(r^{\prime}\right) d r^{\prime}}
$$

where $P_{o}$ is the transmitted laser power in terms of photon counts at $532 \mathrm{~nm}, c$ is the velocity of light, $\tau$ is the pulse duration, $A$ is the effective system receiver area, $\beta(r)$ is the backscattering coefficient, $1 / r^{2}$ is the range dependence factor that accounts for the decrease in solid angle subtended with the square of the range, and $e^{-2 \int_{0}^{r} \sigma\left(r^{\prime}\right) d r^{\prime}}$ is the integrated two-way extinction of the signal as it propagates from the instrument to the scattering volume at range $r$ and returns back. The method mostly used for inverting elastic LIDAR returns is the backward inversion method. The Klett inversion requires an input value of the extinction coefficient at the far boundary of the LIDAR range. This boundary value can be measured or assumed.

The backscattering and extinction coefficients are given by contribution of both aerosols and molecules and are expressed as

$$
\begin{aligned}
& \beta(r)=\beta_{\mathrm{aer}}(r)+\beta_{\mathrm{mol}}(r), \\
& \sigma(r)=\sigma_{\mathrm{aer}}(r)+\sigma_{\mathrm{mol}}(r),
\end{aligned}
$$

where subscripts (aer) and (mol) indicate aerosols and molecules, respectively. Molecular contributions were calculated using data from CIRA 1986 standard atmosphere model $[20,21]$. The molecular backscatter coefficient $\beta_{\text {mol }}(r)$ is estimated by considering the theoretical molecular LIDAR ratio $S_{\mathrm{mol}}=\sigma_{\mathrm{mol}} / \beta_{\mathrm{mol}}$ as $(8 \pi / 3) s r$, under the condition of zero molecular absorption $[20,21]$. The backward inversion method followed is same as earlier research by Bangia et al. $[20,21]$.

The total backscatter coefficients are derived from the backward inversion method and can be expressed as $[20,21]$

$$
\beta_{\mathrm{aer}}(r)+\beta_{\mathrm{mol}}(r)=\frac{X(r) \exp \left[-2\left(S_{\mathrm{aer}}(r)-S_{\mathrm{mol}}\right) \int_{r_{c}}^{r} \beta_{\mathrm{mol}}(r) d r\right]}{X\left(r_{c}\right) /\left(\beta_{\mathrm{aer}}\left(r_{c}\right)+\beta_{\mathrm{mol}}\left(r_{c}\right)\right)-2 S_{\mathrm{aer}}\left\{\int_{r_{c}}^{r} X(r) \exp \left[-2\left(S_{\mathrm{aer}}(r)-S_{\mathrm{mol}}\right) \int_{r_{c}}^{r} \beta_{\mathrm{mol}}\left(r^{\prime}\right) d r^{\prime}\right] d r\right\}},
$$

where $X(r)$ is the range normalized signal given by $P(r) r^{2}$ and $r_{c}$ is the reference height. One advantage of using the backward inversion method is that when we start integrating from the far end of the LIDAR sounding path, we can avoid 


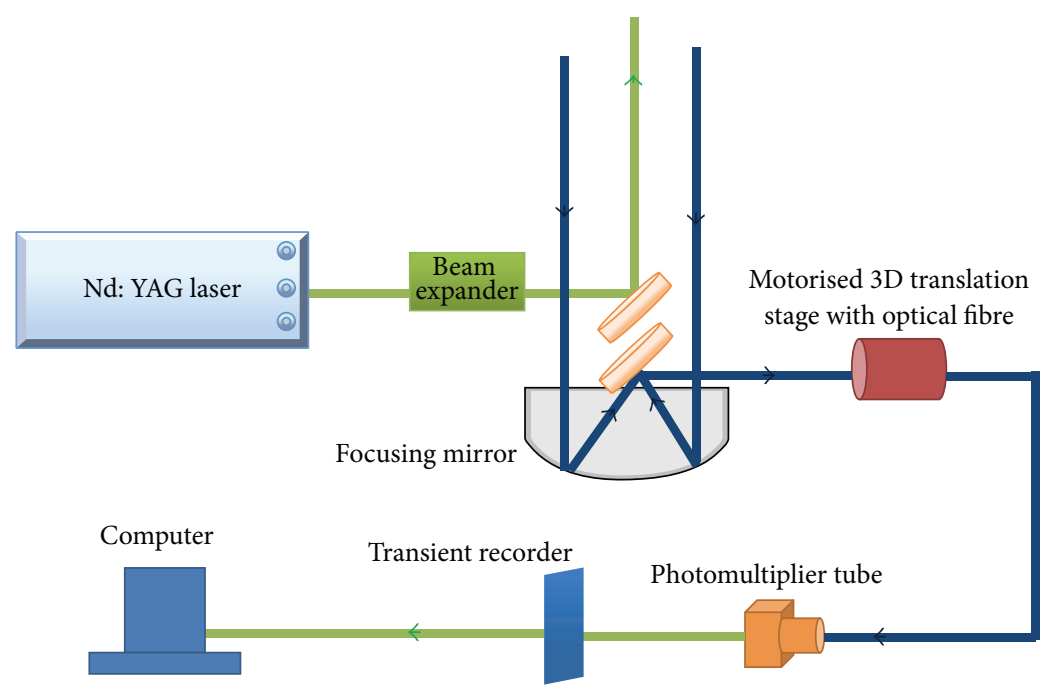

FIgURE 2: Schematic layout of the CSIR-NLC mobile LIDAR system.

producing negative values of $\beta_{\mathrm{aer}}(r)$ [22]. For more details, the reader may refer to Bangia et al. $[20,21]$.

Aerosol optical depth (AOD) is calculated by integrating the extinction coefficient from cloud base to its top [23].

$$
\mathrm{AOD}=\int_{Z_{b}}^{Z_{t}} \alpha(r) d r
$$

where $Z_{t}$ is the cloud top, $Z_{b}$ is the cloud base, and $\alpha(r)$ is the aerosol extinction coefficient.

\section{Results and Discussion}

5.1. CSIR LIDAR Observations. LIDAR measurements were carried out on 20, 21, 22, and 23 November 2012 in Durban (see Figure 3). On 20 November 2012, the backscatter signal from the LIDAR (where red indicates a strong backscatter) revealed the presence of a cloud layer. The cloud was observed at an altitude of around $500 \mathrm{~m}$ from 10:59 until it started raining at around 15:50 local time (see Figure 3(a)). The cloud had a thickness of about $100 \mathrm{~m}$. (Note that the CSIR LIDAR has capability for providing range resolution of $10 \mathrm{~m}$.) On 21 November 2012, two layers of clouds at the heights of 600 and $1400 \mathrm{~m}$ were observed between 10:40 and 12:00 local time (see Figure $3(\mathrm{~b})$ ). The backscatter signal indicated that the lower level cloud at $600 \mathrm{~m}$ did not have a large amount of liquid water content in it, thus allowing the laser to penetrate through it, and enabled the detection of the other layer of clouds at approximately $1400 \mathrm{~m}$. The cloud at a height of $600 \mathrm{~m}$ showed a thickness of about $100 \mathrm{~m}$ while the other layer at a height of $1400 \mathrm{~m}$ indicated a thickness of approximately $70 \mathrm{~m}$. However, the upper cloud layer could not be observed at the local time of 13:01 until 13:45 but a strong backscatter signal was observed at the height of $600 \mathrm{~m}$. This indicates that the laser might not penetrate through the clouds (optically opaque); thus the other layer could not be observed, if there were any. On 22 November 2012, multilayered clouds were briefly observed between 13:10 and 13:28 local time (see Figure 3(c)). The lower level clouds were observed at $600 \mathrm{~m}$ and the upper level clouds were observed at $1000 \mathrm{~m}$ with thickness of about $100 \mathrm{~m}$. On 23 November 2012, a single layer cloud at a height of 10000-12000 m was observed (see Figure 3(d)). The backscatter signal was moderate at a height of $11000 \mathrm{~m}$ and the strength of the signal weakened with increasing height.

A similar method used by Venema et al. [24] to identify clouds directly from the extinction coefficient profiles was used. In this method, the height at which the signal decreases/increases considerably is called cloud top/base. For aerosols, the extinction coefficients profiles generally show a decrease in extinction coefficient values with increasing height and clouds generally show sudden high values on the profile. The aerosol extinction coefficient profiles for 20, 21, 22, and 23 November 2012 are shown in Figure 4. On 20, 21, and 22 November 2012, low level clouds were observed. On these days, an aerosol layer was observed at altitudes of $\sim 100-400 \mathrm{~m}$. On 20 November 2012, a layer of cloud was observed between 400 and $500 \mathrm{~m}$ (see Figure 4(a)) and demonstrated an extinction coefficient value of $0.018 \mathrm{~m}^{-1}$. On 21 November 2012 (see Figure 4(b)), multilayered clouds were also observed. Thin cloud layers at 600, 700, and $800 \mathrm{~m}$ were observed from the extinction coefficient profiles which were not so visible in Figure 4(b). These cloud layers showed extinction coefficients values of $0.003,0.0118$, and $0.0117 \mathrm{~m}^{-1}$, respectively. There was also a cloud layer at $1500 \mathrm{~m}$ with an extinction coefficient value of $0.009 \mathrm{~m}^{-1}$. On 22 November 2012 (see Figure 4(c)), multiple layers of clouds were observed at $600,1000,1200$, and $1500 \mathrm{~m}$ with extinction coefficients values of $0.0012,0.0044,0.0013$, and $0.0009 \mathrm{~m}^{-1}$, respectively. On 23 November 2012 (see Figure 4(d)), cloud layers at 10000 and $11000 \mathrm{~m}^{-1}$ with extinctions coefficients values of 0.000001 and $0.000002 \mathrm{~m}^{-1}$ were observed. The extinction coefficients of low level clouds had values in the range of $0.018-0.0009 \mathrm{~m}^{-1}$ depending upon the thickness of cloud. Thicker clouds showed higher values of extinction coefficients compared to thinner clouds.

The temporal evolution of the aerosol optical depth (AOD) was retrieved for the four days of measurements in 


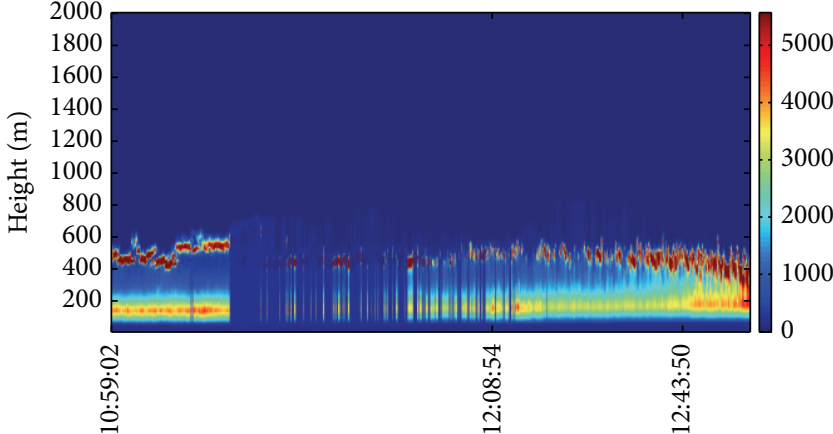

Time (HH:MM:SS)

(a)

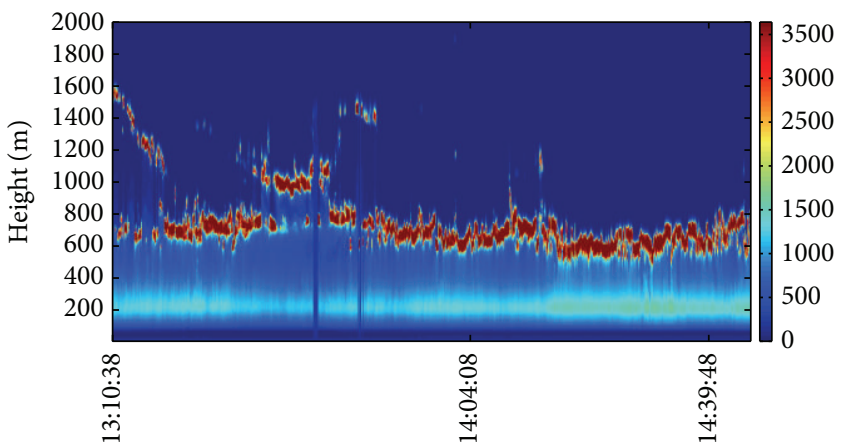

Time (HH:MM:SS)

(c)

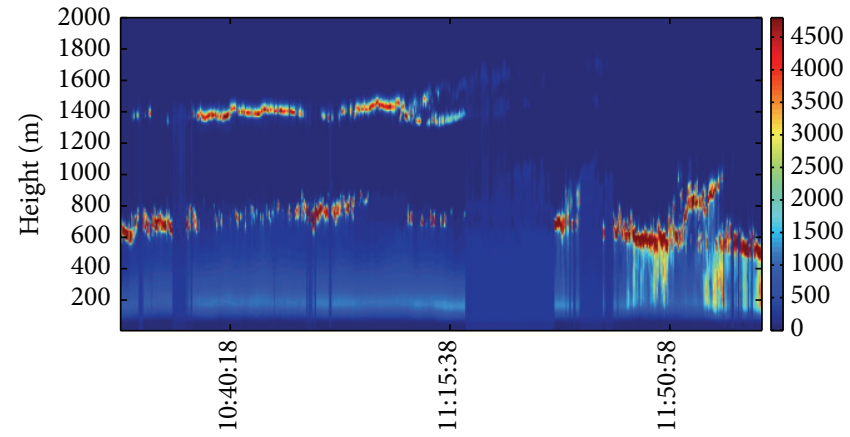

Time (HH:MM:SS)

(b)

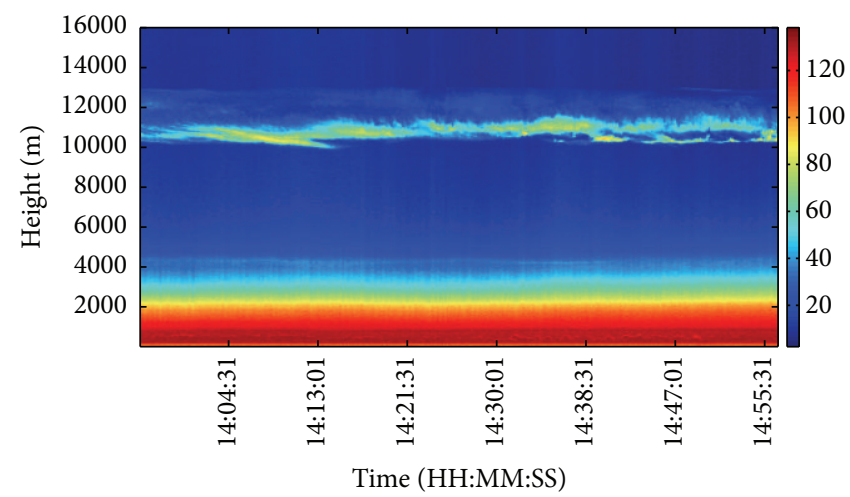

(d)

FIGURE 3: Height-time colour map of CSIR transportable LIDAR backscatter signal returns at daytime in Durban on (a) 20 November 2012, (b) 21 November 2012, (c) 22 November 2012, and (d) 23 November 2012 UTC+02:00.

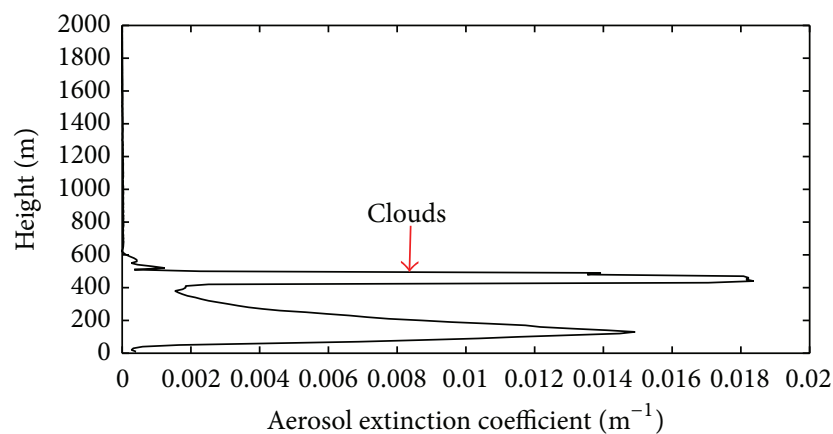

(a)

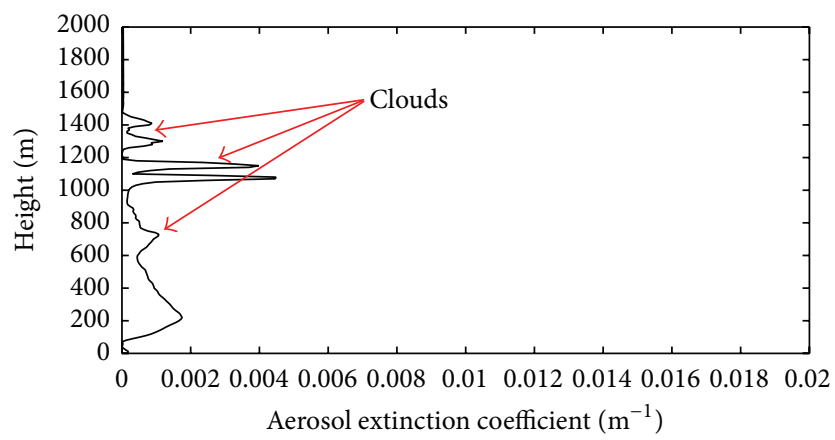

(c)

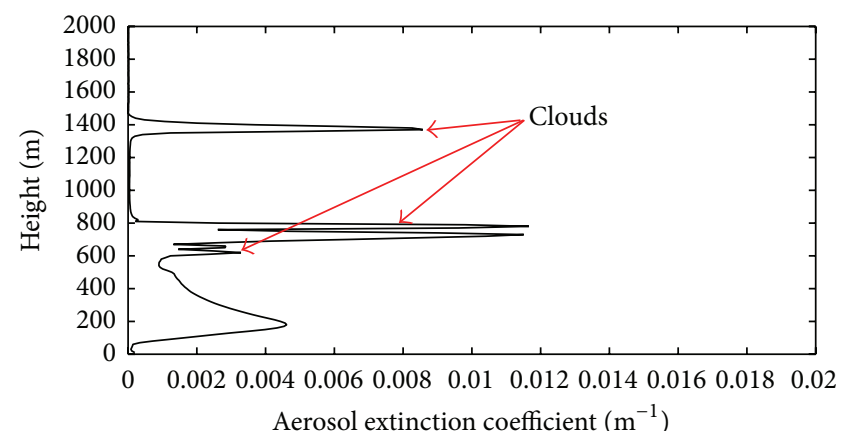

(b)

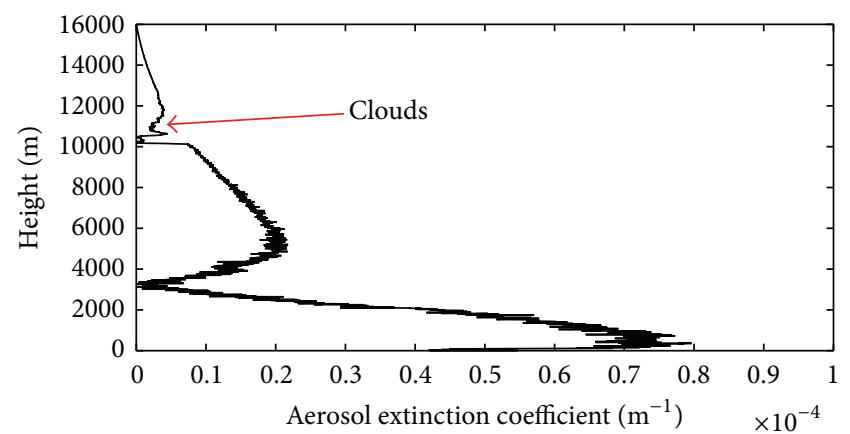

(d)

Figure 4: The retrieved aerosol extinction coefficients using the LIDAR on (a) 20 November 2012, (b) 21 November 2012, (c) 22 November 2012, and (d) 23 November 2012. 


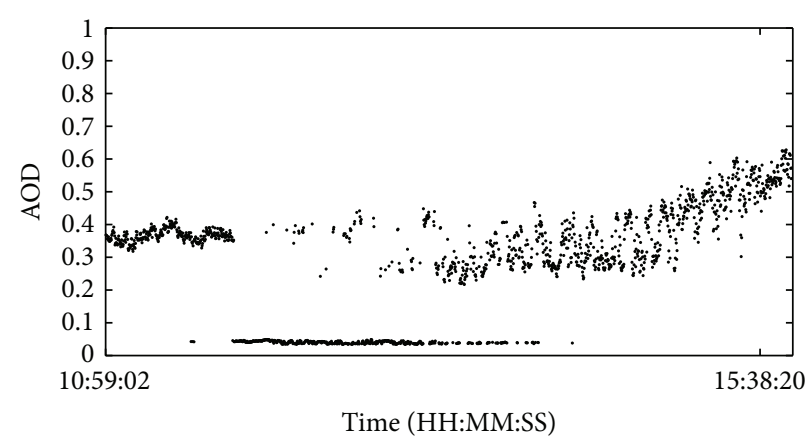

(a)

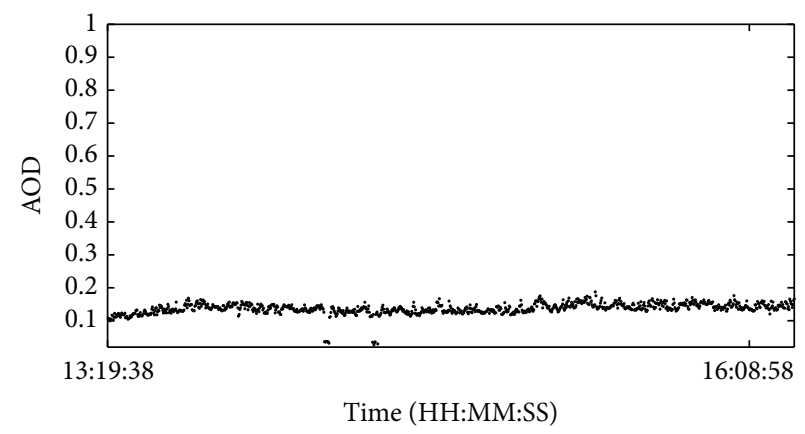

(c)

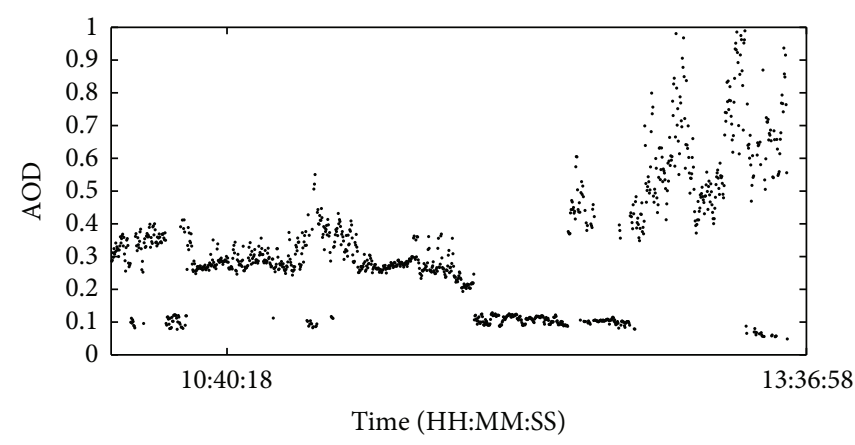

(b)

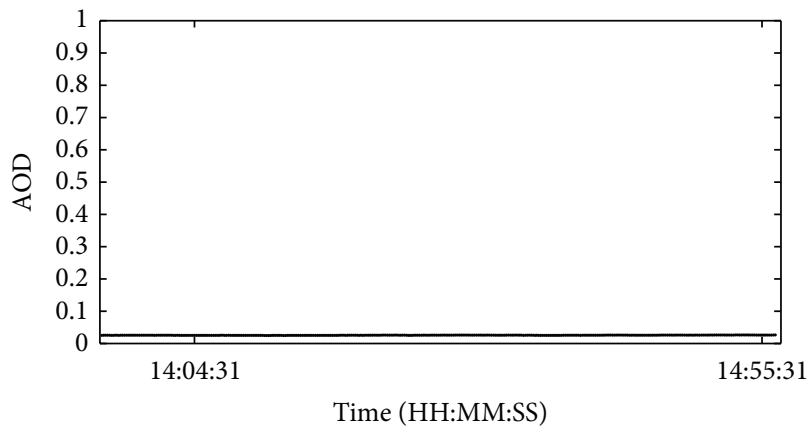

(d)

Figure 5: Temporal evolution of AOD on (a) 20 November 2012, (b) 21 November 2012, (c) 22 November 2012, and (d) 23 November 2012.

Durban (see Figure 5) using equation (4). On 20 November 2012, an overall increase of the AOD was observed from the morning (10:59) to the afternoon (15:40) from 0.35 to 0.6 (see Figure 5(a)). On 21 November 2012, a similar trend was also observed with AOD increasing from 0.3 to 1 (see Figure 5(b)). However, on 22 November 2012, a small change in AOD was observed from 0.1 to 0.15 (see Figure 5(c)). Platt et al. [25] mentioned that the change in optical depth depends on the nature of composition and the thickness of the cloud. However, on 23 November 2012, a steady AOD value of $\sim 0.02$ was observed (see Figure 5(d)).

5.2. Cirrus Clouds Observed on 23 November 2012. Throughout the campaign, cirrus clouds were only observed on 23 November 2012. Most of the clouds are found between the heights of $5.5 \mathrm{~km}$ and $12.5 \mathrm{~km}$, with height range thicknesses spanning 1.8-3.1 km; see Figure 6. Sassen et al. [26] and Jensen et al. [27] have ascribed the outflows from cumulonimbus anvils to the formation of thick cirrus clouds to mid and high altitudes. These type of clouds arise due to the vertical mixing of air from the entrainment and detrainment. It has been previously suggested that the ice water gradient is largely destroyed due to sturdy mixing by the strong cloud circulation [28]. The optical properties of this cloud were compared to cirrus clouds observed in the southern hemisphere; see Table 2. From the reported cirrus clouds in Table 2, it can be seen that the cirrus clouds over Durban had the lowest cloud height base of $5.5 \mathrm{~km}$. These are very low cirrus clouds but over time they were found to disappear. However, the average cloud thickness is similar to that observed by

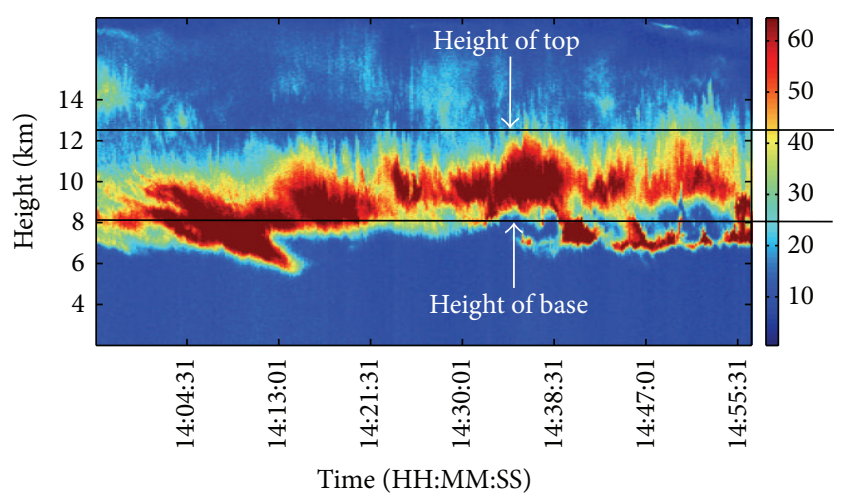

FIGURE 6: Height-time colour map of CSIR transportable LIDAR signal returns, illustrating the presence of cirrus cloud on 23 November 2012 over Durban. The cloud height top and cloud height bottom are indicated by the thick dark lines.

Lakkis et al. [10]. This correlation does somehow suggest that the cirrus cloud properties may depend on climate conditions and geographical location. However, a more wider climatological study needs to be carried out to confirm the dependence of climate conditions and geographical location.

5.3. CALIPSO and CSIR LIDAR Comparison. The only comparable CALIPSO data which were available during the operation of the CSIR LIDAR were on 20 and 22 November 2012. For 21 and 23 November 2012, the satellite observations were too far from the measurement site. Figures 7 (a) and 7(b) show 
TABLE 2: Cirrus cloud properties observed by LIDAR.

\begin{tabular}{|c|c|c|c|c|c|}
\hline & $\begin{array}{c}\text { Location (AGL) } \\
\text { (distance from shoreline) }\end{array}$ & $\begin{array}{l}\text { Cloud top height } \\
(\mathrm{km}) \text {, maximum }\end{array}$ & $\begin{array}{l}\text { Cloud base height } \\
(\mathrm{km}) \text {, minimum }\end{array}$ & $\begin{array}{l}\text { Cloud thickness } \\
(\mathrm{km})\end{array}$ & $\begin{array}{c}\text { Distance to } \\
\text { tropopause }(\mathrm{km})\end{array}$ \\
\hline Durban & $\begin{array}{c}29.9^{\circ} \mathrm{S}, 30.9^{\circ} \mathrm{E} \\
(8 \mathrm{~m}) \\
( \pm 14 \mathrm{~km})\end{array}$ & 12.5 & 5.5 & 2.45 & - \\
\hline $\begin{array}{l}\text { (Buenos Aires) } \\
\text { Lakkis et al., } 2009 \text { [10] }\end{array}$ & $\begin{array}{c}34.6^{\circ} \mathrm{S}, 58.5^{\circ} \mathrm{W} \\
(31 \mathrm{~m})\end{array}$ & 11.82 & 9.63 & 2.41 & 0.38 \\
\hline $\begin{array}{l}\text { (Punta Arenas) } \\
\text { Immler and Schrems, } \\
2002[15]\end{array}$ & $\begin{array}{l}53.1^{\circ} \mathrm{S}, 71^{\circ} \mathrm{W} \\
(30 \mathrm{~m})\end{array}$ & 9.5 & 8.8 & 1.4 & 1.7 \\
\hline
\end{tabular}

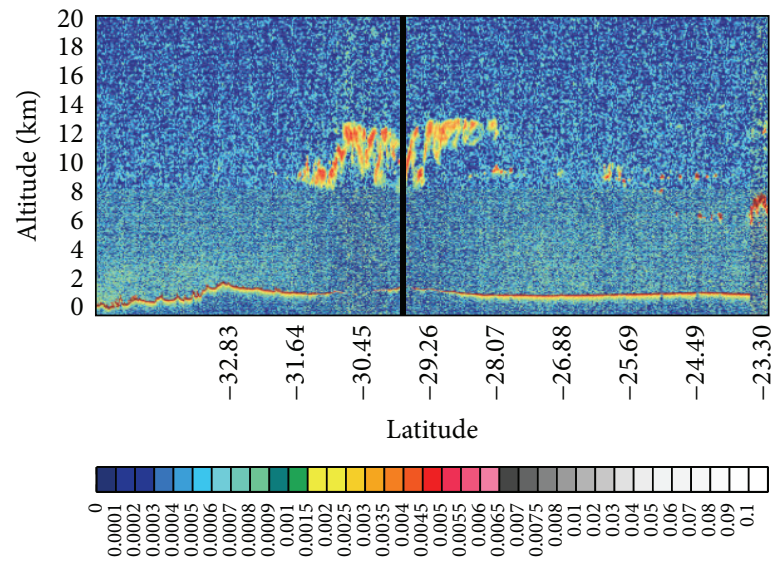

(a)

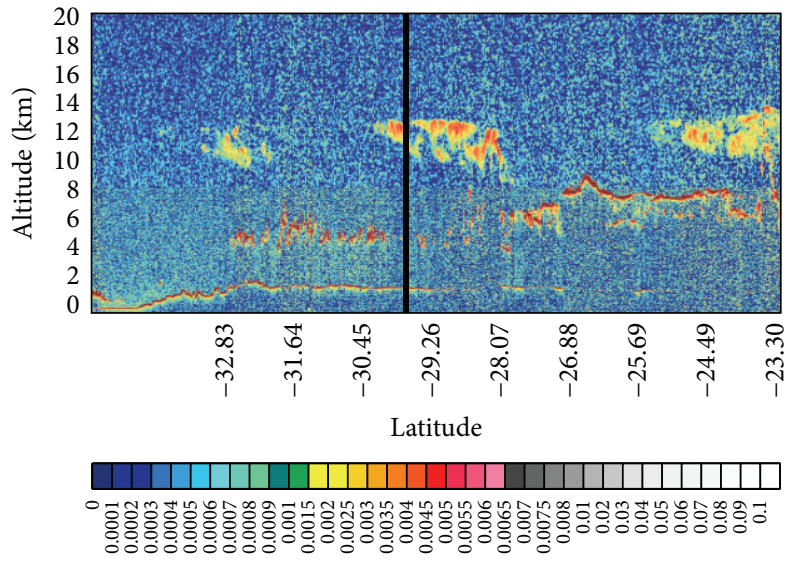

(b)

Figure 7: Height-time colour map of CALIPSO-derived total attenuated backscatter at $532 \mathrm{~nm}$ on (a) 20 November 2012 at 12:05 and (b) 22 November 2012 at 11:52 UTC+02:00.

colour coded time-height images of the daytime level 1 data at $532 \mathrm{~nm}$ acquired by CALIPSO on 20 and 22 November 2012, respectively. On 20 November 2012, the nearest coincidence between the CSIR LIDAR and the CALIPSO occurred at around 12:05 local time. The aerosol layer was observed at around $1 \mathrm{~km}$. No clouds were observed in the lower part of the troposphere by the CALIPSO at the observation site (latitude $-29.9^{\circ}$ ). However, it has illustrated the presence of clouds at $8-13 \mathrm{~km}$ with a thickness of $\sim 3 \mathrm{~km}$; these clouds were not observed by the CSIR LIDAR system. This suggests that the thick cloud observed by the CSIR LIDAR caused most of the photons of the laser to be absorbed and thus a few photons penetrating through the cloud. As a result, these few photons could not detect the clouds at those heights as they could have been scattered or absorbed along the way. On 22 November 2012, a similar cloud at a height of $8-13 \mathrm{~km}$ was observed. However, on this day, a layer of cloud was observed at the height of $\sim 4.5 \mathrm{~km}$ by the CALIPSO. The CSIR LIDAR gives a better description of the atmospheric conditions in the first few kilometers of the troposphere for cloudy conditions whereas the CALIPSO gives better information at the top of the troposphere. Further, it indirectly also addresses the strength of the signal which is higher at lower heights (as it is penetrating upward) while the satellite data looks downward where the signal strength is higher at the top. Thus, the two instruments complement each other to give a description of clouds in the troposphere even for cloudy conditions.

The mean extinction coefficient profiles from the CALIPSO level 2 aerosol product are shown in Figure 8. On 20 November 2012, the highest value of extinction coefficient of $\sim 0.08 \mathrm{~km}^{-1}$ was observed at a height of about $5 \mathrm{~km}$ (see Figure 8(a)). From Figure 8(a), this indicates the presence of a thin cloud at that altitude. High level clouds at the heights of $6-11 \mathrm{~km}$ were observed from the extinction coefficient data. However, on the lower part of the troposphere, a thick single layer of cloud at around $1.8 \mathrm{~km}$ was observed. It can also be observed that different layers of clouds were present at different altitudes from $1.8 \mathrm{~km}$ to $11 \mathrm{~km}$. These, however, were not so clear in Figures 3(a) and 3(c). The negative extinction coefficient values are found to be noise in the CALIPSO signal when aerosol loading is low and background noise is high. On 22 November 2012, the extinction coefficient profile showed the presence of a thick cloud at around $3 \mathrm{~km}$ (see Figure 7(b)) while the aerosol layer was observed at about $1.5 \mathrm{~km}$. However, no extinction coefficients were observed at high altitudes indicating the absence of clouds.

\section{Conclusion}

Campaign measurements over Durban $\left(29.9^{\circ} \mathrm{S}, 30.9^{\circ} \mathrm{E}\right)$ have been carried out due to favourable meteorological conditions 


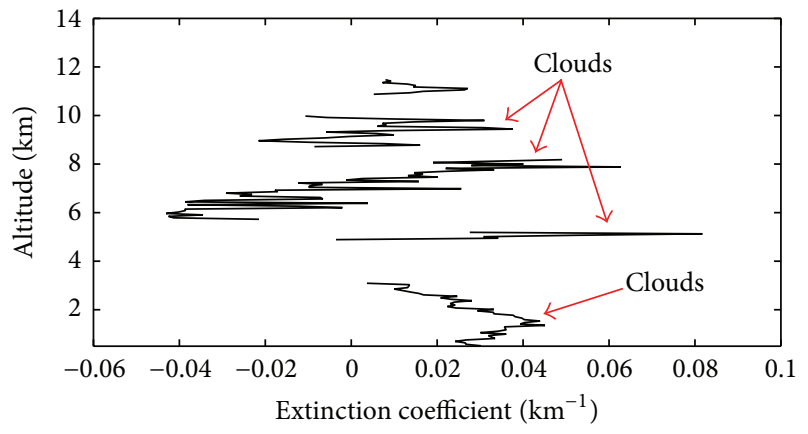

(a)

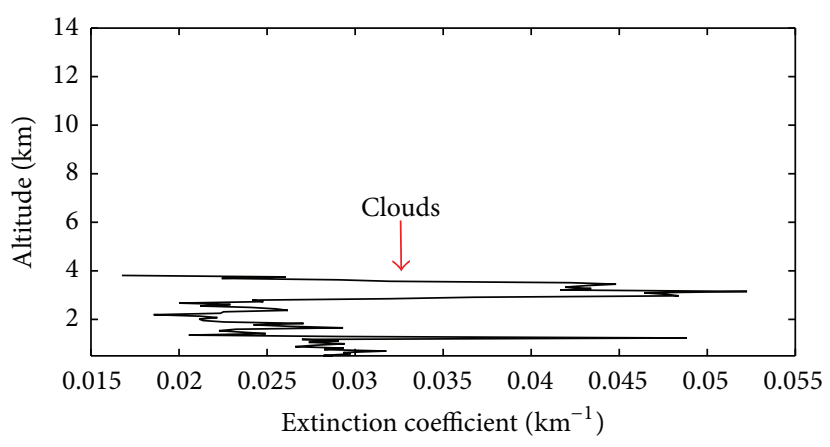

(b)

FIGURE 8: Height profile of extinction coefficient observed from CALIPSO on (a) 20 November 2012 and (b) 22 November 2012.

for cloud formations and to perform aerosol-cloud interactions studies in future. Clouds over Durban $\left(29.9^{\circ} \mathrm{S}, 30.9^{\circ} \mathrm{E}\right)$ during the spring (early summer) season were observed using a transportable LIDAR system. Cloud layers on the lower atmosphere were observed on 20-22 November 2012 while high level clouds were observed on 23 November 2012. The low level cloud layers have high extinction coefficients values ranging from 0.0009 to $0.0044 \mathrm{~m}^{-1}$, whereas low extinction coefficients for high level clouds were observed at values ranging between 0.000001 and $0.000002 \mathrm{~m}^{-1}$. The vast difference in the extinction coefficient suggests that there are remarkable differences in optical characteristics between low and high level clouds. The high level clouds could be classified as cirrus clouds based on the altitude they were detected at. The calculated AOD showed a high variability for 20 and 21 November 2012. This indicates a change in the composition and/or thickness of the cloud. However, a constant value of the optical depth on 23 November suggested a static cloud composition and/or thickness. Comparable LIDAR and CALIPSO data was available on 20 and 22 November 2012 and indicated that the CALIPSO could observe highlevel clouds while the CSIR LIDAR could not. However, the two instruments complement each other well to describe the cloudy condition.

\section{Competing Interests}

The authors declare that they have no competing interests.

\section{Acknowledgments}

The authors would like to thank Henk van Wyk and Ameeth Sharma for the technical support on the LIDAR system. CALIPSO data were obtained from the NASA Langley Research Centre Atmospheric Science Data Centre; the authors would like to acknowledge the NASA personnel for the production of the data used in the present research. The authors would also like to thank the African Laser Centre (ALC) project for funding the campaign measurements in Durban.

\section{References}

[1] G. Jedlovec, "Automated detection of clouds in satellite imagery," in Advances in Geoscience and Remote Sensing, pp. 303-316, InTech, Rijeka, Croatia, 2009.

[2] H. Du, Y. Wang, and Y. Chen, "Studies on cloud detection of atmospheric remote sensing image using ICA algorithm," in Proceedings of the 2nd International Congress on Image and Signal Processing (CISP '09), pp. 1-4, IEEE, Tianjin, China, October 2009.

[3] Y. J. Moghaddam and M. Aghamohamadnia, "A novel method for cloud detection in MODIS imagery," International Archives of the Photogrammetry, Remote Sensing and Spatial Information Sciences, vol. XL-1/W3, pp. 221-224, 2013.

[4] F. Waquet, J. Riedi, L. C. Labonnote et al., "Aerosol remote sensing over clouds using a-train observations," Journal of the Atmospheric Sciences, vol. 66, no. 8, pp. 2468-2480, 2009.

[5] M. Setvák, K. Bedka, D. T. Lindsey et al., "A-Train observations of deep convective storm tops," Atmospheric Research, vol. 123, pp. 229-248, 2013.

[6] F. Madonna, A. Amodeo, A. Boselli et al., "CIAO: the CNRIMAA advanced observatory for atmospheric research," Atmospheric Measurement Techniques, vol. 4, no. 6, pp. 1191-1208, 2011.

[7] J. L. Guerrero-Rascado, M. J. Costa, A. M. Silva, and F. J. Olmo, "Retrieval and variability analysis of optically thin cloud optical depths from a Cimel sun-photometer," Atmospheric Research, vol. 127, pp. 210-220, 2013.

[8] S. Hollars, Q. Fu, J. Comstock, and T. Ackerman, "Comparison of cloud-top height retrievals from ground-based $35 \mathrm{GHz}$ MMCR and GMS-5 satellite observations at ARM TWP Manus site," Atmospheric Research, vol. 72, no. 1-4, pp. 169-186, 2004.

[9] B. V. Hai, D. V. Trung, N. X. Tuan, D. D. Thang, and N. T. Binh, "Monitoring cirrus cloud and tropopause height over Hanoi using a compact LIDAR system," Communications in Physics, vol. 22, no. 4, pp. 357-364, 2012.

[10] S. G. Lakkis, M. Lavorato, and P. O. Canziani, "Monitoring cirrus clouds with lidar in the Southern Hemisphere: a local study over Buenos Aires. 1. Tropopause heights," Atmospheric Research, vol. 92, no. 1, pp. 18-26, 2009.

[11] M. Costa-Surós, J. Calbó, J. A. González, and J. Martin-Vide, "Behavior of cloud base height from ceilometer measurements," Atmospheric Research, vol. 127, pp. 64-76, 2013. 
[12] R. K. Kanike and V. Sivakumar, Remote Sensing of Aerosol Using a Sunphotometer, 2015.

[13] M. Kottek, J. Grieser, C. Beck, B. Rudolf, and F. Rubel, "World map of the Köppen-Geiger climate classification updated," Meteorologische Zeitschrift, vol. 15, no. 3, pp. 259-263, 2006.

[14] A. Moorgawa, H. Bencherif, M. M. Michaelis, J. Porteneuve, and S. Malinga, “The Durban atmospheric LIDAR," Optics \& Laser Technology, vol. 39, no. 2, pp. 306-312, 2007.

[15] F. Immler and O. Schrems, "LIDAR measurements of cirrus clouds in the northern and southern midlatitudes during INCA $\left(55^{\circ} \mathrm{N}, 53^{\circ} \mathrm{S}\right)$ : a comparative study," Geophysical Research Letters, vol. 29, no. 16, pp. 56-1-56-4, 2002.

[16] V. Sivakumar, "CSIR-NLC mobile LIDAR for atmospheric remote sensing," in Remote Sensing-Advanced Techniques and Platforms, B. Escalante-Ramirez, Ed., chapter 13, pp. 289-312, InTech, Rijeka, Croatia, 2012.

[17] A. Sharma, V. Sivakumar, C. Bollig, C. van der Westhuizen, and D. Moema, "System description of the mobile LIDAR of the CSIR, South Africa," South African Journal of Science, vol. 105, no. 11-12, pp. 456-462, 2009.

[18] F. G. S. Lopes, G. L. Mariano, E. Landulfo, and V. C. Mariano, "Impacts of biomass burning in the atmosphere of the southeastern region of Brazil using remote sensing systems," in Atmospheric Aerosols-Regional Characteristics-Chemistry and Physics, F. J. S. Lopes, G. L. Mariano, E. Landulfo, and E. V. C. Mariano, Eds., pp. 978-953, InTech, Rijeka, Croatia, 2012.

[19] B. Medeiros, L. Nuijens, C. Antoniazzi, and B. Stevens, "Lowlatitude boundary layer clouds as seen by CALIPSO," Journal of Geophysical Research: Atmospheres, vol. 115, no. 23, Article ID D23207, 2010.

[20] T. Bangia, A. Omar, R. Sagar et al., "Study of atmospheric aerosols over the central Himalayan region using a newly developed Mie light detection and ranging system: preliminary results," Journal of Applied Remote Sensing, vol. 5, no. 1, Article ID 053521, pp. 1-12, 2011.

[21] T. Bangia, A. Kumar, R. Sagar, P. K. Agarwal, and S. K. Singh, "Development of Mie LIDAR system and initial cloud observations over Central Himalayan region," Scientific Research and Essays, vol. 6, no. 4, pp. 896-907, 2011.

[22] D. Stoyanov, I. Grigorov, G. Kolarov, Z. Peshev, and T. Dreischuh, "LIDAR atmospheric sensing by metal vapor and Nd:YAG lasers," in Advanced Photonic Sciences, M. Fadhali, Ed., chapter 14, pp. 345-374, InTech, Rijeka, Croatia, 2012.

[23] V. Krishnakumar, M. Satyanarayana, S. R. Radhakrishnan et al., "Lidar investigations on the optical and dynamical properties of cirrus clouds in the upper troposphere and lower stratosphere regions at a tropical station, Gadanki, India $\left(13.5^{\circ} \mathrm{N}, 79.2^{\circ} \mathrm{E}\right)$, Journal of Applied Remote Sensing, vol. 8, no. 1, Article ID 083659, pp. 1-21, 2014.

[24] V. Venema, H. Russchenberg, A. Apituley, A. van Lammeren, and L. Ligthart, "Cloud boundary height measurements using lidar and radar," Physics and Chemistry of the Earth, Part B: Hydrology, Oceans and Atmosphere, vol. 25, no. 2, pp. 129-134, 2000.

[25] C. M. R. Platt, J. D. Spinhirne, and W. D. Hart, "Optical and microphysical properties of a cold cirrus cloud: evidence for regions of small ice particles," Journal of Geophysical Research, vol. 94, no. 8, pp. 11151-11164, 1989.

[26] K. Sassen, A. W. Huggins, A. B. Long, J. B. Snider, and R. J. Meitin, "Investigations of a winter mountain storm in Utah. Part II: mesoscale structure, supercooled liquid water development, and precipitation processes," Journal of Atmospheric Sciences, vol. 47, pp. 1323-1350, 1990.

[27] E. J. Jensen, O. B. Toon, H. B. Selkirk, J. D. Spinhirne, and M. R. Schoeberl, "On the formation and persistence of subvisible cirrus clouds near the tropical tropopause," Journal of Geophysical Research: Atmospheres, vol. 101, no. 16, pp. 21361-21375, 1996.

[28] V. Sivakumar, Y. Bhavanikumar, P. B. Rao et al., "Lidar observed characteristics of the tropical cirrus clouds," Radio Science, vol. 38, no. 6, article 1094, 2003. 

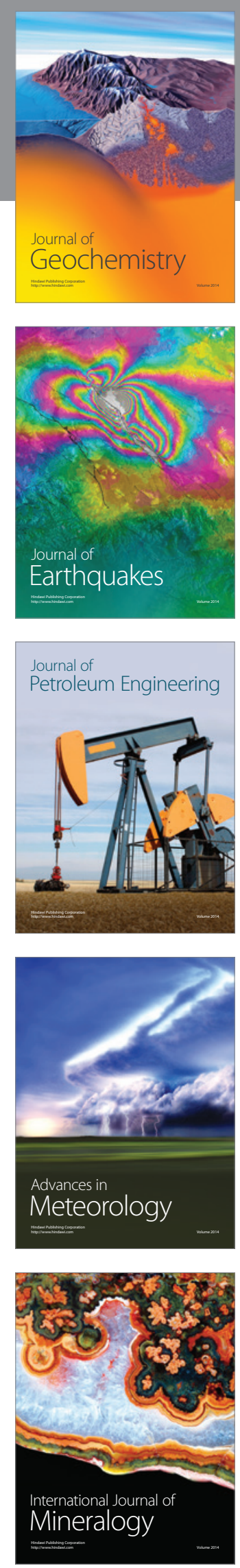
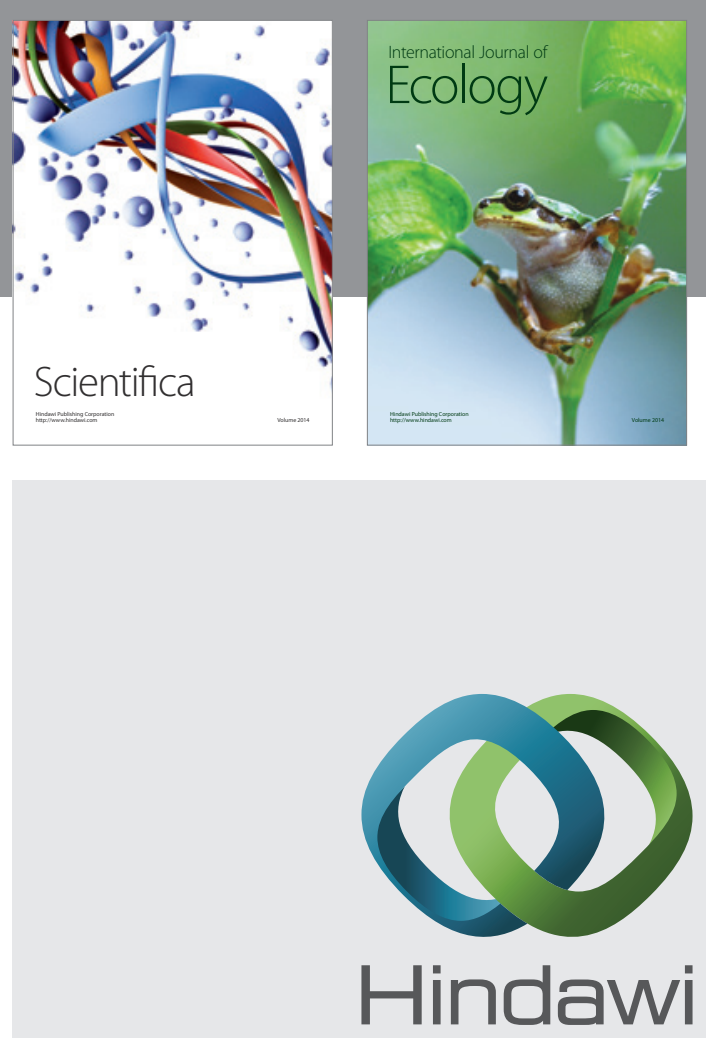

Submit your manuscripts at

http://www.hindawi.com
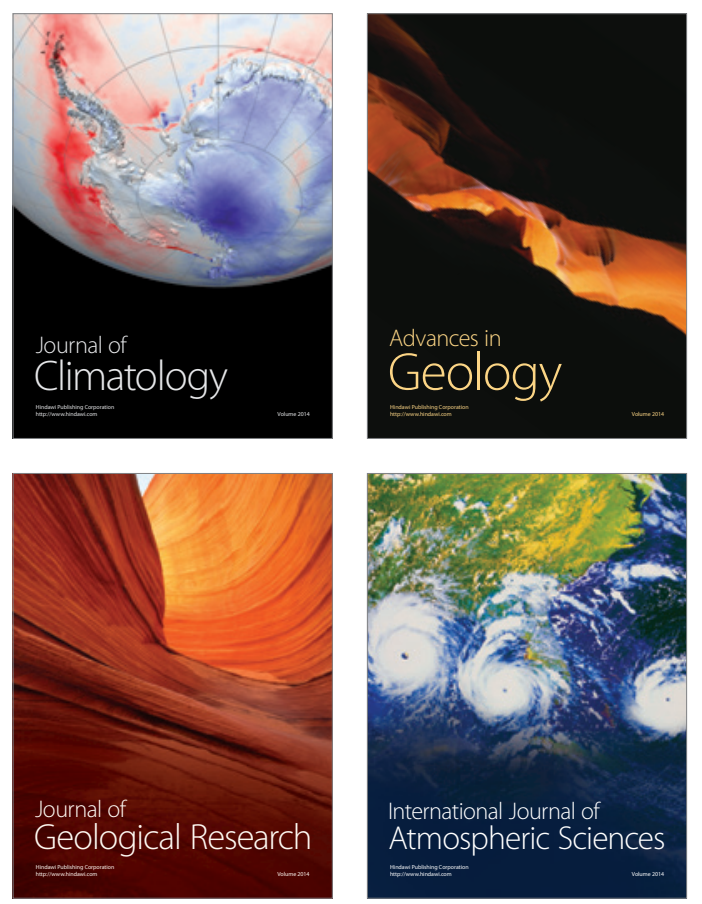

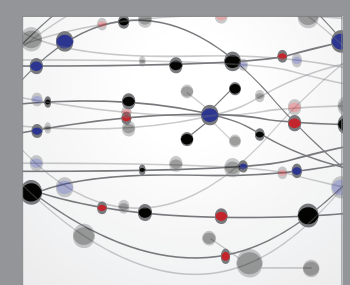

The Scientific

\section{World Journal}
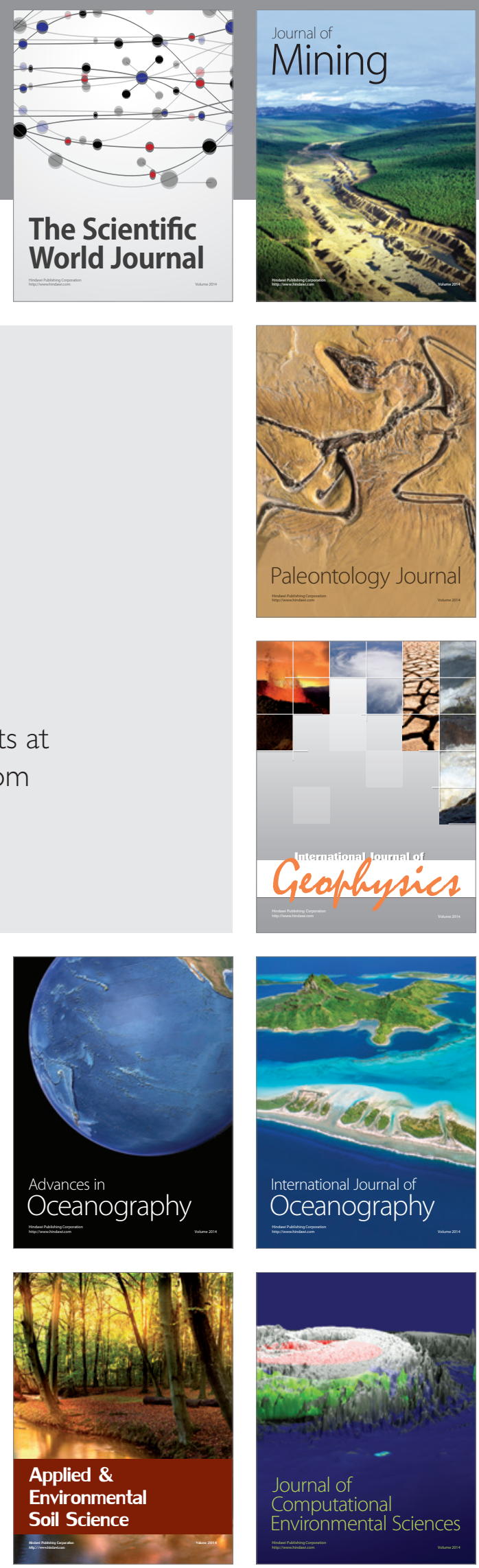